\title{
Affects, resources, culture and perceived health: what is the relationship among them?
}

\author{
Ma Dolores Merino*, Jesús Privado, and Zeus Gracia
}

Universidad Complutense de Madrid, Madrid (Spain)

\begin{abstract}
Título: Afectos, recursos, cultura y salud percibida: ¿cuál es la relación entre ellos?.

Resumen: El propósito de esta investigación es comprender si la relación entre el afecto positivo y negativo (AP/AN) y la salud percibida está mediada por los recursos psicosociales, y, si la cultura (colectivista vs. individualista) tiene un rol en esta relación. Se aplicaron diferentes Modelos de Ecuaciones Estructurales: el primero recoge relaciones directas e indirectas entre AP/AN y salud, y el segundo, refleja la influencia indirecta de $\mathrm{AP} / \mathrm{AN}$ sobre salud y la mediación de los recursos entre ambos. Los modelos fueron probados en dos culturas: individualista (España) y colectivista (México). Los resultados muestran que España no hay diferencias significativas entre los dos modelos, sin embargo, en México, el modelo con relaciones directas e indirectas ajusta mejor a los datos. Estos resultados tienen interesantes implicaciones: 1) La influencia de AP/AN sobre la salud puede ser diferente dependiendo de la cultura, por tanto, tener en consideración la variable cultura en este tipo de investigaciones podría ser una cuestión relevante. 2) La forma en la que AP y AN influyen sobre la salud percibida es distinta; el AP influye tanto directa como indirectamente a través de los recursos, mientras que AN solo influye directamente. Sería muy interesante que futuras investigaciones replicaran este estudio considerando más países, y, empleando parámetros biológicos de salud.
\end{abstract}

Palabras claves: Afecto positivo y negativo; salud; recursos psicosociales; probabilidad percibida de contagio.

\section{What is positive and negative affect?}

According to the study of positive and negative affect (Watson, Clark \& Tellegen, 1988), it is generally accepted that: 1) Positive affect (PA) promotes pleasurable feelings, while negative affect (NA) cultivates unhappiness. More specifically, "PA reflects the extent to which a person feels enthusiastic, active, and alert. High PA is a state of high energy, full concentration, and pleasurable engagement, whereas low $P A$ is characterized by sadness and lethargy. In contrast, $N A$ is a general dimension of subjective distress and unpleasurable engagement that subsumes a variety of aversive mood states, including anger, contempt, disgust, guilt, fear, and nervousness, with low NA being a state of calm and serenity" (p.1063). 2) Although there is a wide variety of PA and NA, there isn't a unique repertory. Nevertheless, one of the most employed PA/NA repertories is the Positive and Negative Affect Scale (PANAS) (Crawford \& Henry 2004). 3) PA and NA can be a state or trait. This means that, as a state, affect is a very temporary feeling strongly linked to an event, and, as a trait, it is a long term feeling which reflects the person's typical emotional style, and consequently his personality. 4) PA and NA are relatively independent. The question is to determine whether PA and NA are the opposite poles of one dimension, or two different dimensions. The research on this topic

* Correspondence address [Dirección para correspondencia]:

$\mathrm{M}^{\mathrm{a}}$ Dolores Merino. Universidad Complutense de Madrid. Facultad de Psicología. Departamento de Personalidad, Evaluación y Tratamiento Psicológico II (Ps. Diferencial y del Trabajo). Campus de Somosaguas, 28223, Pozuelo de Alarcón, Madrid (Spain).

E-mail: lolamerino@psi.ucm.es
Abstract: The purpose of this research is to understand if the relationship between positive and negative affect $(\mathrm{PA} / \mathrm{NA})$ and perceived health is mediated by psychosocial resources, and, whether culture (collectivistic vs. in dividualistic) has a role in that relationship. Structural Equation Models were applied: The first expressed the direct and indirect relationship $\mathrm{PA} / \mathrm{NA}$ to health. The second reflected indirect influence of PA/NA on health and, resources mediated between both. Both models were tested in two cultures: one individualistic (Spain) and the other collectivistic (Mexico). The results showed that models work differently in both cultures. In Spain there were no significant differences between the two models. In Mexico, the direct and indirect relationship model functioned better. These results have interesting implications: The influence of $\mathrm{PA} / \mathrm{NA}$ on health could be different depending on the culture, therefore future research to reconsider the cultural variable, would be interesting. The way PA vs. NA influence perceived health is different; PA can influence both directly and indirectly through psychosocial resources, while NA can only influence directly. It would be fascinating if future research would replicate this, including more countries, and, using biological measurements of health.

Key words: Positive and negative affect; health; psychosocial resources; perceived probability of contagion.

supports that PA and NA are relatively independent. This means they are different constructs but present some correlations between .20 and .50 in most cases (Diener \& Emmons, 1984; Watson et al., 1988).

Psychology traditionally has paid more attention to the study of NA (Fredrikson, 2001). Nevertheless in the last decades, the research of PA has clearly increased (Diener \& Chan, 2011). One of the most studied areas has been the relationship between PA/NA and health.

\section{Negative and Positive affect and health}

Related to the study of the association between affect and health, we can consider two perspectives depending on the way health has been measured: objective and subjective. Objective measures use biological parameters while subjective are based on people's perception of the state of health.

Specially documented and well established has been relations between NA and cardiovascular problems (Kubzansky, Kawachi, Weiss \& Sparrow, 1998; Todaro, Shen, Niaura, Spiro \& Ward, 2003) and the immune system. The latter is one of the most interesting lines of research because the decrease of immune response has a large range of potential morbidity implications. For example, some evidence shows how depression can stimulate the production of proinflammatory cytokines which influence some diseases associated with aging such as: cardiovascular disease, osteoporosis, arthritis, type 2 diabetes, certain cancers, periodontal disease, frailty, and functional decline. Moreover, the decrease of immune responses prolonged infection, delayed wound 
healing, and, made the person more susceptible to viral infections (Glaser \& Kiecolt-Glaser, 2005; Kiecolt-Glaser \& Glaser, 2002; Kiecolt-Glaser, McGuire, Robles \& Glaser, 2002).

Different revisions have well-documented the association between PA and health (Diener \& Chan, 2011; Lyubomirsky, King \& Diener, 2005; Pressman \& Cohen, 2005). These studies show the close association of PA to lower mortality rate, less morbidity, and greater longevity (Cohen \& Pressman, 2006; Pressman \& Cohen, 2005). One of the most famous studies is known as "The Nun Study". In this investigation, the researchers analysed the PA included in the nuns' writings made when they entered their religious life. An association between the PA expressed in those papers and the nuns' longevity was found; the nuns with positive writings lived an average of 6.9 years longer (Danner, Snowdon \& Friesen, 2001). Other interesting results showed that PA was related to lower mortality rate in both healthy and diseased populations (Chida \& Steptoe, 2008). And, Pressman and Cohen (2005) concluded that PA improved long-term survival prognosis in some illnesses, such as early stage breast cancer, coronary heart disease and AIDS, but worsened in other more serious illnesses such as melanoma, metastatic breast cancer and end-stage renal disease. The reason may be that people with $\mathrm{PA}$ tend to perceive fewer symptoms, which in turn may affect treatment choices by doctors.

Other interesting evidence observes that PA is associated to the immune system making viral infections less probable. An example is one of the most cited studies developed by Cohen, Doyle, Turner, Alper and Skoner (2003). The results show, that PA was associated with lower risk of colds. Three years later, Cohen, Alper, Doyle, Treanor and Turner (2006) replicated this study but using used different viruses in a smaller sample. The result was basically the same as found in the previous study.

All of these studies show that PA/NA can be related to objective physical health. But, how people perceive their physical health is also very relevant. People behave according to their perceptions, and not according to objective facts. Subjective health can even be associated to objective health. Some studies have discovered that optimistic expectations predict immune system changes and health (Segerstrom \& Sephton, 2010). So, the study of antecedents and consequences of perceived physical health is also of great relevance.

Several investigations have found an association between affects and perceived health; positive in the case of PA and negative in the case of NA (Cloninger \& Zohar, 2011). Other studies have shown that people with PA described fewer symptoms than they actually had, and the contrary occurred in people with NA (Cohen et al., 2003; Cohen et al, 2006). These results are explained because high NA people tend to be more self-centered, so any internal change is interpreted as important (Pennebaker, 2000). Nevertheless, high PA people are more focused externally on other people and en- vironmental stimuli. Moreover, high PA is connected to more social and psychological resources (Fredrikson, 2001). The social resources allow people to have more support in case of illness and the psychological resources provide better coping ability with disease. The opposite occurs in the case of high NA, which is associated with lost resources (Hobfoll, 1989; 2002).

\section{Affect, psychosocial resources and health}

Psychosocial resources are related to the physical and mental health of individuals (Hobfoll, 2002). In 1989, Ryff developed a model composed of five psychological resources: 1) self-acceptance: knowledge and positive attitude of self, acceptance good and bad qualities and positive feelings about the life in the past; 2) autonomy: perceived psychological self-government or self-determination; 3) environmental mastery: ability to monitor, manage and effectively model the activities and demands of everyday life, and to live in harmony with one's goals, needs and values; 4) purpose in life: striving for and achieving goals give purpose to life; 5) personal growth: To develop their potential, to continue growing as a person and to maximize their capabilities; and 6) positive relations with others: To have trustworthy friends, stable relationships and social support. These six constructs constituted a second order factor called psychological well-being. The relationships between this general construct and their six dimensions with health are well documented in different research (Ryff, 2013). For, example, Ryff, Singer \& Love (2004) found correlations between psychological well-being and diverse biomarkers in a sample of older woman. They found that those with higher scores in psychological well-being (mainly in purpose in life and personal growth) had lower levels of salivary cortisol throughout the day. Higher levels of environmental mastery, selfacceptance and positive relations with others, in turn, were linked with better glycemic control (measured as glycosylated hemoglobin). Higher personal growth and purpose in life also present higher levels of "good" cholesterol.

Moreover, according to "The Broaden and Build Theory of Positive Emotions" (Fredrickson, 2001) a close relationship exists between positive emotions, resources and positive consequences. This theory is structured in three steps: broad, build and transform. According to the same theory, positive emotions broaden an individual's thought-action repertoire contributing to building personal resources and transforming the person, allowing a better ability to cope with life difficulties. In others words, positive emotions promote the creation of solid resources that enable desirable outcomes such as health, wealth and longevity (Fredrickson, 2001). Therefore it is possible that resources could mediate the relationship between PA and health. On the other hand, The Conservation of Resources Theory of Hobfoll (1989) states that people strive to obtain, maintain and protect resources. When resources are threatened or lost due to adverse events, a chain of losses occurs, producing poor adap- 
tation to the environment, with negative consequences such as stress. The opposite occurs in the case of gains or resource creation. When resources which are perceived as threatened, or possibly lost due to adverse events, a chain of losses occurs. The result is poor adaptation to the environment, with negative consequences such as stress. In the case of NA we can conclude that resources don't mediate the relationship with health.

According to the above statements, affects, resources and health are linked. But, it is also possible that this relationship is influenced by culture.

\section{Cultural Differences}

One of the dimensions frequently used to study differences among cultures is individualism versus collectivism. This construct emerges using different measurements, samples or time periods (Kuppens, Realo \& Diener, 2008). According to Green, Deschamps and Paez (2005) Western context, such as Western Europe, North America or Australia is basically individualistic, whereas non-Western areas like Asia, South America or Africa are described as collectivistic. Individualistic cultures are characterized by: "independence, autonomy, self-reliance, uniqueness, achievement orientation, and competition. Collectivism in turn, is associated with a sense of duty toward one's group, interdependence with others, a desire for social harmony, and conformity with group norms" (p. 322). The key resources in one kind of culture and another are different and it is also possible with the impact of PA and NA, since high PA people are sociable, while high NA people are more selfcentered (Pennebaker, 2000). Therefore NA clearly works contrary to the central resource in collectivistic societies, while PA works in favor.

Considering all aforementioned information, the objective of this research is to understand whether the relationship between PA/NA and perceived health could be mediated by psychosocial resources, and, if relationships (among those variables) are different depending on the culture: collectivistic (Mexico) versus individualistic (Spain).

\section{Method}

\section{Sample}

The sample was composed of 130 Spanish psychology college students and 184 Mexican psychology college students. For Spanish colleges, the average age was 19.9 years $(\mathrm{SD}=1.26)$, with $76.6 \%$ being women. For Mexican colleges, the average age was $21.13(\mathrm{SD}=2.23)$, with $80.8 \%$ women.

\section{Procedure}

The data was collected as follows: In Spain, the sample was shared with two groups of 33 participants and two groups of 32. In Mexico there were eight groups of 23 par- ticipants. Each session lasted one hour. All measurements were self-reported.

\section{Measures}

Psychosocial Resources: To measure psychosocial resources, we use the reduced version of the Spanish adaptation of the Psychological Well-Being Scale (Diaz et al., 2006), originally proposed by Ryff (1988). This scale measures six first order factors, which correspond to five psychological resources (selfacceptance, autonomy, environmental mastery, personal growth, and purpose in life) and one social resource (positive relationships with others), and, a second order factor called Psychological Well-being. This scale is composed of 29 items. Levels of fit and internal consistency of the scales are suitable (Diaz et al., 2006).

Positive and Negative Affect: To assess PA and NA we used the Spanish adaptation of the Positive and Negative Affect Schedule (PANAS) given by Sandín, Chorot, Lostao, Joiner, Santed \& Valiente (1999). The adaptation of this measure, like the original version (Watson et al., 1988), is composed of two scales of 10 items each, one for PA and one for NA. The psychometric properties of the Spanish version are appropriate (Sardin et al., 1999). The PANAS can measure affect as a trait or as a state. The association between PA/NA and health is clearer in the case of trait than in the case of state (Cohen \& Pressman, 2006) and due to that, we used the trait version.

Perceived Health: Inspired by the idea that expectations can be associated with objective health (Segerstrom \& Sephton, 2010), and, in the fact that people with weak immune systems, would be more probable to be infected by a virus (Glaser \& Kiecolt-Glaser, 2005), three self- reported sentences were used. People had to report the degree of agreement or disagreement on a 5 -point scale. The items were: "I am a person prone to catch colds and flu"; "When someone close to me is suffering from an infection, it is easy for me to catch it"; "Every winter I catch bad colds".

We applied Exploratory Factor Analysis (maximum likelihood) to the three items in the Spanish sample and Confirmatory Factor Analysis in the Mexican sample (see results), and we found similar results.

In both countries, the three items were grouped in one factor that we called "Perceived Probability of Contagion" (PPC). This factor explained the $75.59 \%$ of the variance in Spain and $61.93 \%$ in Mexico. The Cronbach's Alfa was .90 in Spain and .83 in Mexico.

To measure the criterion validity of PPC, we included in our study a question asking participants if they had had to be home sick during the academic year, they have to answer yes or no. We found significant differences in PPC in Spain $\left(t_{128}\right.$ $=2.154, p=.033)$ and Mexico $\left(\left(t_{179}=3.012, p=.003\right)\right.$. That means participants who scored higher on perceived likelihood of contagion, in fact, were home sick more often than those who scored lower on PPC. And this constitutes a test of criterion validity to our PPC measurement. 


\section{Statistical analysis}

Structural Equation Model was applied to observe the relationship among the constructs: $\mathrm{PA} / \mathrm{NA}$, psychosocial resources and PPC. All statistical analyses were performed with AMOS 7.0 (Arbuckle, 2006). These techniques require at least three measurement indicators to accurately estimate the latent factors, with a minimum of 100 participants, and 10 times the number of observed variables. This study used a sample of 130 participants for Spain and a total of 10 indicators, which are $130 / 10=13$ participants per indicator (Byrne, 2001), adequate values. And for Mexico we used a sample of 184 participants: $184 / 10=18.4$ participants people per indicator.

The procedure used to fit the models was maximum likelihood based on the $\chi^{2}$ test. The goodness of fit statistics used to evaluate the adequacy of the models were: absolute, incremental and parsimony. The value of the absolute fit of the model to empirical data indicates the statistic $\chi^{2}$. If it is statistically significant, the null hypothesis would be rejected, therefore the matrix theoretical and empirical data would be unequal. However, the null hypothesis is commonly rejected with large samples, so the ratio $\chi^{2} / \mathrm{df}$ (Bentler \& Bonett, 1980 ) is often used, indicating a good fit with values less than 3. Another absolute fit index is: Root Mean Square Error of Approximation (RMSEA) (Steiger, 1990). The RMSEA values below .05 indicate good fit.
Incremental fit measures compare the resulting model and allow the null model. Normed Fit Index (NFI) of Bentler and Bonett (1980) and Comparative Fit Index (CFI) of Bentler (1990) are the most frequently used, and values above .95 indicate good fit and then the empirical model is significantly different from the null model.

Parsimony fit measures evaluate the model fit versus the estimated number. They take into account the complexity of the hypothesized model in the assessment of overall model fit. More representative coefficients are Parsimony Goodness of Fit Index (PGFI) of Jöreskog and Sörbom (1993) and Parsimony Normed Fit Index (PNFI) of James, Mulaik and Brett (1982). Values above .50 indicate good fit.

\section{Results}

\section{Correlation matrix}

Table 1 shows the correlations among the different measures used in this study, and the Cronbach's alpha. Values in the correlation matrix are over .30; this implies the presence of a latent factor (Hair, Black, Babin, Anderson \& Tatham, 2006). The reliabilities of the tests are acceptable; almost all measures have values over .70 (Abad, Olea, Ponsoda \& García, 2011).

Table 1. Correlations between variables, and, Cronbach's alfa $(\alpha)$. In bold font the results of Spain. In normal font the results of Mexico.

\begin{tabular}{|c|c|c|c|c|c|c|c|c|c|}
\hline & 1 & 2 & 3 & 4 & 5 & 6 & 7 & 8 & 9 \\
\hline 1. PA & & -.462 & -.167 & .363 & .587 & .648 & .616 & .667 & .404 \\
\hline 2. NA & -.406 & & .262 & -.460 & -.551 & -.447 & -.473 & -.534 & -.376 \\
\hline 3. PPC & -.287 & .308 & & -.078 & -.073 & -.112 & -.168 & -.127 & -.098 \\
\hline 4. Autonomy & .471 & -.341 & -.100 & & .516 & .406 & .386 & .520 & .344 \\
\hline 5. Environmental mastery & .565 & -.472 & -.233 & .351 & & .713 & .639 & .717 & .496 \\
\hline 6. Purpose in life & .659 & -.334 & -.181 & .343 & .608 & & .630 & .775 & .409 \\
\hline 7. Personal growth & .333 & -.298 & -.262 & .213 & .263 & .342 & & .648 & .507 \\
\hline 8. Self-acceptance & .564 & -.534 & -.186 & .424 & .560 & .671 & .324 & & .458 \\
\hline 9. Positive relationships & .274 & -.295 & -.134 & .091 & .285 & .253 & .235 & .390 & \\
\hline$\alpha$ & .764 & .795 & .900 & .818 & .718 & .777 & .710 & .849 & .805 \\
\hline$\alpha$ & .840 & .888 & .825 & .713 & .666 & .847 & .829 & .864 & .767 \\
\hline
\end{tabular}

* Correlations $\geq|.181|$ are statistically significant, $p<.05$.

\section{Structural Equation Models}

With the purpose of knowing whether the influence of $\mathrm{PA} / \mathrm{NA}$ on PPC is direct, or mediated by resources, we tested two structural equations models: The first expressed the direct and indirect relationship of PA/NA on PPC. The second reflected indirect influence of PA/NA on PPC and, resources mediated between both. Figure 1 shows both models, the Spanish sample and Figure 2 the Mexican sample. 


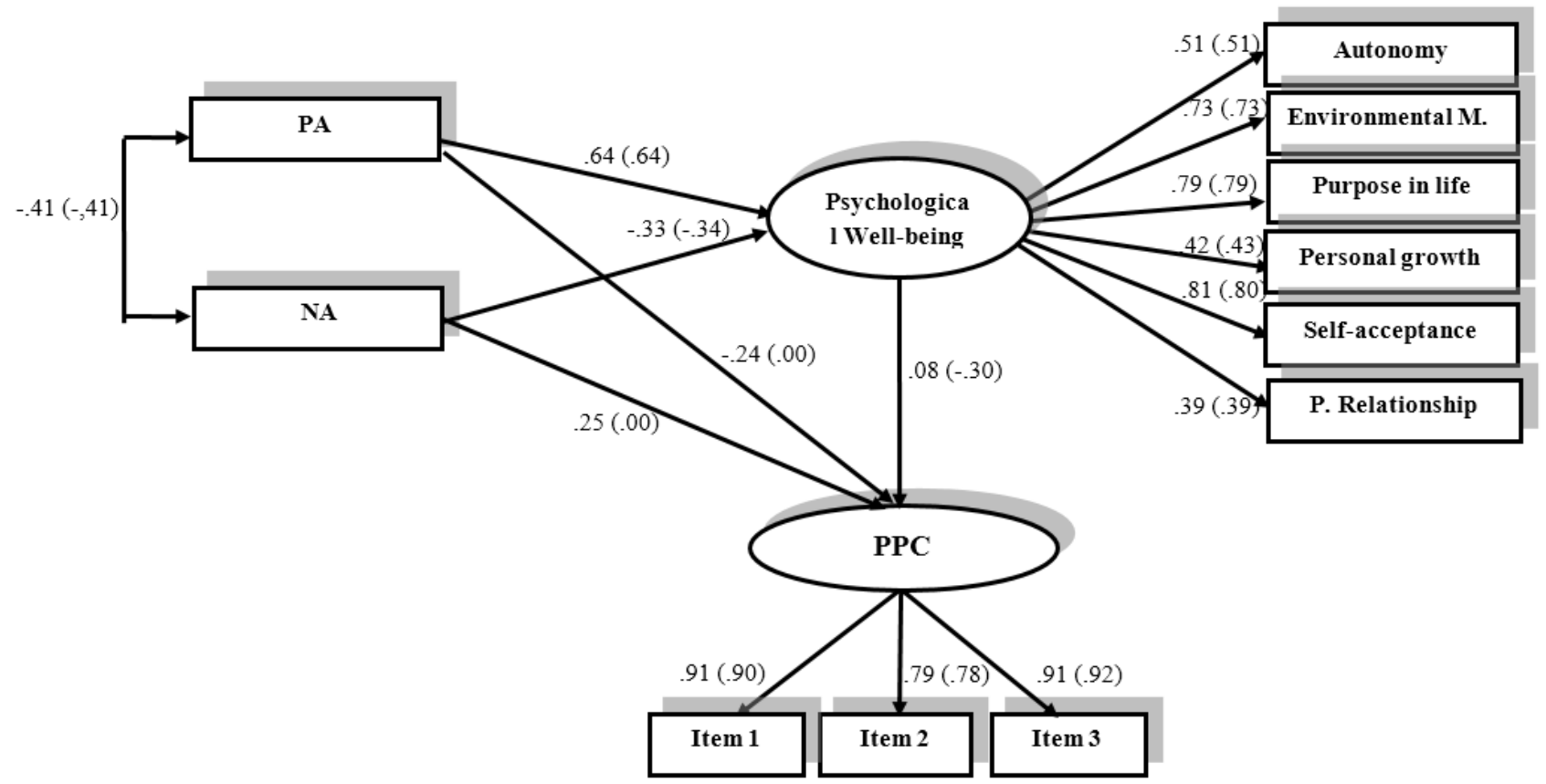

Figure 1. Models for the Spanish sample: Without parenthesis, direct and indirect relationship of PA on PPC, and, with parenthesis, indirect relationship model. Correlations higher than $|.24|$ are significant statistically $(p<.05)$.

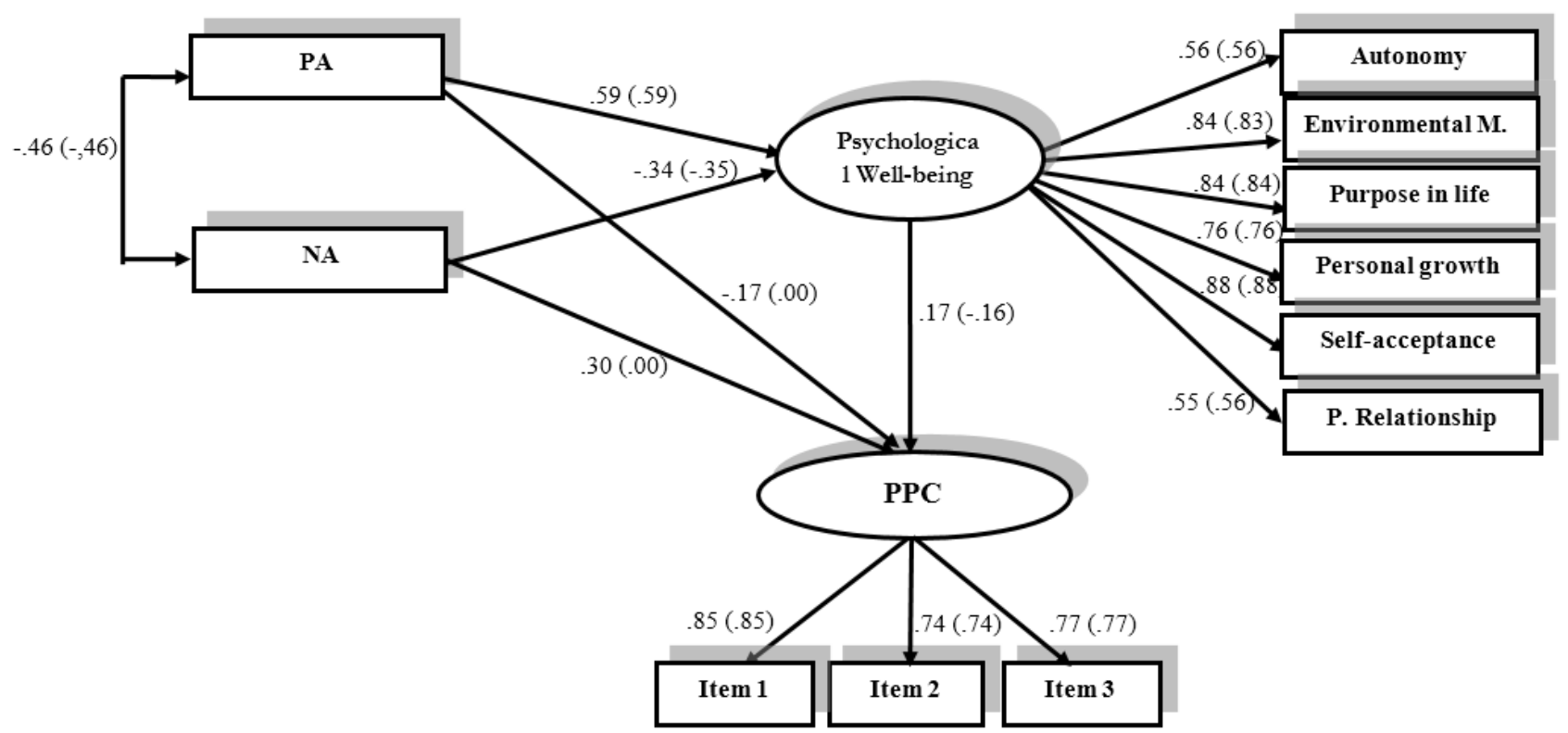

Figure 2. Models for the Mexican sample: Without parenthesis, direct and indirect relationship of PA on PPC, and, with parenthesis, indirect relationship model. Correlations higher than $|.24|$ are significant statistically $(p<.05)$.

\section{Results for the Spanish sample}

In the first model (direct and indirect relationship of $\mathrm{PA} / \mathrm{NA}$ on PPC) the absolute goodness of fit index $\chi^{2}$ showed that the model did differ significantly from the empirical data $\left[\chi^{2}(40)=58.36, p=.030\right]$ but the ratio $\chi^{2} / d f$ was 1.459 , less than 3 , indicating good fit. The RMSEA value was .060 , indicating good fit with the proposed factor struc- ture. The incremental fit indices showed good fit, NFI value was .913 and CFI value was .970, therefore the empirical model was significantly different from the null model. The parsimony fit indices had values higher than .50 and PNFI was .664, also showing good model fit. Therefore, according to the goodness of fit indices, we can conclude that this first structural equation model has a good fit with empirical data. 
The second model (indirect influence of PA/NA on PPC) was equal to the first model, but by setting regression weights of PA/NA on PPC to zero. That is to say, it was a nested model in the first model (direct and indirect relations model). In this case the adjustment was also suitable: $\chi^{2}(42)$ $=64.02, p=.016$; ratio $\chi^{2} / d \mathrm{f}=1.524$; RMSEA $=.064 ; \mathrm{NFI}$ $=.905 ; \mathrm{CFI}=.964$ and $\mathrm{PNFI}=.691$.

It is necessary to know if there are statistical differences between both models since they are both nested. In case of differences, we are left with the best fit model, (the direct and indirect relationships model). In the event that there are no differences, we are left with the most parsimonious (the indirect relationships model) because it has fewer parameters. To verify that both models are equivalent, they must be compared if the difference is statistically significant $\chi^{2}$ (Yung, Thissen \& McLeod, 1999): $\Delta \chi^{2}=\chi^{2}(42)-\chi^{2}(40)=64.02-$ $58.36=5.66, p>.05$. There are no significant differences between the two models.

Given the sensitivity of $\chi^{2}$ to sample size, it is necessary to calculate the difference of Tucker-Lewis Index (TLI), a difference greater than .01 is considered statistically significant (Gignac, 2007). $\Delta$ TLI $=.959-.953=.006$. We found no significant differences. Therefore, the second and most parsimonious model is more appropriate for the Spanish sample (indirect influence of affect on PPC). According to this result, PA/NA is directly related to well-being, and indirectly to PPC. More concretely, PA influence on well-being is .64 while the influence of NA on the same variable is -.34. So, PA has almost double weight in the indirect relationship on PPC than NA. Considering the weight sign, more PA indicates more psychosocial resources while more NA fewer psychosocial resources. The relationship between well-being and PPC is -.30 . All these associations are significant statistically $(p<.05)$.

\section{Results for the Mexican sample}

As is shown in Figure 2, the results have good fit with respect to the direct and indirect relationship model: $\chi^{2}(40)$ $=53.65, p=.073$; ratio $\chi^{2} / d \mathrm{f}=1.341 ; \mathrm{RMSEA}=.043$; NFI $=.949 ; \mathrm{CFI}=.986$; and PNFI $=.575$. In respect to the indirect relationship model, the fit was: $\chi^{2}(42)=62.95, p=.020$; ratio $\chi^{2} / d \mathrm{f}=1.499 ; \mathrm{RMSEA}=.052 ; \mathrm{NFI}=.940 ; \mathrm{CFI}=$ .979 ; and PNFI $=.598$. This result confirms the factorial structure of PPC found in the Spanish sample. Comparing both nested models we find statistically significant differences between them $\left[\chi^{2}: \Delta \chi^{2}=\chi^{2}(42)-\chi^{2}(40)=62.95-\right.$ $53.65=9.30, p<.01]$. Moreover, the TLI difference between models is superior to $.01[\Delta \mathrm{TLI}=.977-.966=.011]$, so, we chose the direct and indirect relationship model because it has better fit than with the indirect relationship model. This means that in the Mexican sample, NA has a direct influence on PPC (.30), but almost nothing on PA (.17); the weight isn't statistically significant. Moreover, PA/NA influence psychological well-being $(r=.59$ and $r=-$
.34 , respectively), but well-being almost has no influence on PPC (.17).

\section{Discussion}

Taking the four models together we observe that they have several things in common: 1) PA and NA are related within the expected range; between .20 and .50 (Diener \& Emmonds, 1984; Watson et al., 1988); 2) PA and NA influence psychological well-being (composed of six psychosocial resources), but, the PA influence is double that of NA. Transcultural research has found the same result related to the relationship between PA/NA and well-being (Suh, Diener, Oishi, \& Triandis, 1998); 3) the PA weight over psychological well-being is positive. This is consistent with Fredrickson (2001) who states that the role of PA contributes to the build of resources; and 4) the weight of NA over psychological well-being is negative and this is consistent with Hobfoll (1989) who considers that stress is associated to resources loss, so more NA fewer resources.

On the other hand, if we observe the psychosocial resources weights, we notice that positive relations with others has more weight in Mexico (.55) than in Spain (.39) and this is not surprising considering that Mexico is a collectivistic culture (Kuppens, Realo, \& Diener,2008). Nevertheless we also find higher weight in personal growth in the Mexican sample, but the reason for this is unclear.

\section{Comparison among structural equation models in both cultures}

Considering the comparison of both models in Spain, the results indicate that there aren't any differences between the direct and indirect relationship model, and indirect relationship model. That means PA/NA has a direct influence on PPC (direct and indirect relationship model), but at the same time, psychosocial resources have a mediator role in the relationship between affects and PPC (indirect relationship model). Nevertheless, when we compare both models in Mexico, there are significant differences between them. Furthermore, the best fit is the direct and indirect relationship model. Unlike in Spain, the only influence comes from NA and psychological well-being (psychosocial resources) which have no mediator role in the relationship between affects and perceived health.

To understand what is happening, we must compare the models in both countries. We find that the influence of $\mathrm{PA} / \mathrm{NA}$ over PPC is different in both cultures. In Mexico, the association between NA and PPC is twice of PA (.30 to NA and -.17 to PA). The association between PA and PPC is not significant. In Spain, the influence of PA/NA over PPC is almost equal (.25 to NA and -.24 to PA). We consider this difference critical to understanding the differences between both cultures. In others words, only NA in Mexico is affecting perceived health, while in Spain, the influence of PA/NA on PPC is similar. This could explain that the re- 
sources do not act as mediators in the Mexican indirect relationship model. In Mexico, the influence the PA has over perceived health is not significant. So, it is logical that in the Mexican indirect relationship model, the resources are unable to act as mediators. This result is concordant with Conservation of Reources Theroy of Hobfoll (1989), according to which NA is related to lost resources, and, also with The Broaden-and-Build theory of Fredrikson (2001), which said that the function of PA is the development of resources which have positive consequences, such as health for example.

\section{Conclusions and future research}

There are differences in the relationship between PA/NA, and perceived health in Spain and Mexico. NA has much more influence over perceived health in Mexico while PA has no influence. Thus the consequences of affects may be

\section{References}

Abad, F. J., Olea, J., Ponsoda, V., \& García, C. (2011). Medición en ciencias sociales y de la salud. Madrid: Síntesis.

Arbuckle, J. L. (2006). Amos 7.0 User's Guide. Chicago: SPSS.

Bentler, B. M., \& Bonett, D. G. (1980). Significance tests and goodness of fit in the analysis of covariance structures. Psychological Bulletin, 88, 588606. doi: 10.1037/0033-2909.88.3.588

Bentler, P. M. (1990). Comparative fit indexes in structural models. Psychological Bulletin, 107, 238-246. doi: 10.1037/0033-2909.107.2.238

Byrne, B. M. (2001). Structural equation modeling with AMOS basic concepts, applications, and programming. New Jersey: Lawrence Erlbaum.

Chida, Y., \& Steptoe, A. (2008). Positive psychological well-being and mortality: a quantitative review of prospective observational studies. Psychosomatic medicine, 70(7), 741-756. doi: 10.1097/PSY.0b013e31818105ba

Cloninger, C. R., \& Zohar, A. H. (2011). Personality and the perception of health and happiness. Journal of affective disorders, 128, 1, 24-32. doi: 10.1016/j.jad.2010.06.012

Cohen, J. (1988). Statistical power analysis for the behavioural sciences $\left(2^{\mathrm{a}} \mathrm{ed}.\right)$. Hillsdale, NJ: Erlbaum.

Cohen, S, A., Doyle, W. J., Treanor, J. J., \& Turner, R. B. (2006). Positive emotional style predicts resistance to illness after experimental exposure to rhinovirus or influenza A virus. Psychosomatic Medicine, 6, 809-815. doi: 10.1097/01.psy.0000245867.92364.3c

Cohen, S. A. \& Pressman, S. D. (2006). Positive Affect and Health. Current Directions in Psychological Science, 3, 122-125. doi: 10.1111/j.09637214.2006.00420.x

Crawford, J. R., \& Henry, J. D. (2004). The Positive and Negative Affect Schedule (PANAS): Construct validity, measurement properties and normative data in a large non-clinical sample. British Journal of Clinical Psychology, 43, 3, 245-265. doi: 10.1348/0144665031752934

Danner, D. D., Snowdon, D. A., \& Friesen, W. V. (2001). Positive emotions in early life and longevity: findings from the nun study. Journal of personality and social psychology, 80(5), 804. doi: 10.1037/0022-3514.80.5.804

Díaz, D., Rodríguez-Carvajal, R., Blanco, A., Moreno-Jiménez, B., Gallardo, I., Valle, C., \& van Dierendonck, D. (2006). Adaptación española de las escalas de bienestar psicológico de Ryff. Psicothema, 18, 572-577.

Diener, E. \& Chan, M.Y. (2011). Happy People Live Longer: Subjective Well-Being

Contributes to Health and Longevity. Applied Psychology: Health and Well-Being, 1, 1-43. doi: 10.1111/j.1758-0854.2010.01045.x

Diener, E., \& Emmons, R. A. (1984). The independence of positive and negative affect. Journal of Personality and Social Psychology, 47, 1105-1117. doi: 10.1037/0022-3514.47.5.1105 different depending on the culture. Although literature indicates that both variables influence health, most studies have been conducted in Western Culture, ignoring the cultural variable. It would be interesting if future research reconsiders this.

There are differences in the way PA and NA relate to perceived health. PA related directly to PPC, and, indirectly through psychosocial resources, while NA had mainly a direct effect. It would be of interest if future research replicates this, but using biological measurement of health.

The results of this study are based on the comparison of two cultures; one collectivistic (Mexico), and, the other individualistic (Spain). Nevertheless, Spain like Southern European countries, is not a pure prototype of individualistic culture. With that in mind, it could be beneficial if future research replicates this, including countries such as: USA, Netherlands or Germany.

Dockray, S. \& Steptoe, A. (2010). Positive affect and psychobiological processes. Neurosci. Biobehav. Rev., 1, 69-75. doi: 10.1016/j.neubiorev.2010.01.006

Fang, C. Y., Miller, S. M., Bovbjerg, D. H., Bergman, C., Edelson, M. I., Rosenblum, N. G., Bove, B. A., Godwin, A. K., Campbell, D. E., \& Douglas, S. D. (2008). Perceived stress is associated with impaired Tcell response to HPV16 in women with cervical dysplasia. Annals of behavioral medicine, 35(1), 87-96.

Fredrickson, B. L. (2001). The role of positive emotions in positive psychology: The broaden-and-build theory of positive emotions. American Psychologist, 56, 218 -226. doi: 10.1037/0003-066X.56.3.218

Glaser, R., \& Kiecolt-Glaser, J. K. (2005). Stress-induced immune dysfunction: implications for health. Nature Reviews Immunology, 5, 3, 243-251.

Gignac, G. E. (2007). Multi-factor modelling in individual differences research: Some suggestions and recommendations. Personality and Individual Differences, 42, 37-48.

Green, E. G., Deschamps, J. C., \& Paez, D. (2005). Variation of individualism and collectivism within and between 20 countries a typological analysis. Journal of Cross-Cultural Psychology, 36, 3, 321-339. doi: $10.1177 / 0022022104273654$

Hair, J. F., Black, W. C., Babin, B., Anderson, R. E., \& Tatham, R. L. (2006). Multivariate Data Analysis (6th Edition). New Jersey: Pearson.

Hobfoll, S. E. (1989). Conservation of resources: A new attempt at conceptualizing stress. American psychologist, 44, 3, 513. doi: 10.1037/0003066X.44.3.513

Hobfoll, S. E. (2002). Social and psychological resources and adaptation. Review of General Psychology, 6, 4, 307-324. doi: 10.1037/1089-2680.6.4.307

Iraurgi, I. (2012). Calidad de Vida como indicador de resultados en Salud. Calidad de vida, inclusión social y procesos de intervención, 9, 61.

James, L. R., Mulaik, S. A., \& Brett, J. M. (1982). Causal analysis: models, assumptions and data. Beverly Hills, CA: Sage.

Jöreskog, K.G., \& Sörbom, D. (1993). LISREL 8: user's guide. Chicago: Scientific Software International.

Kiecolt-Glaser, J. K., \& Glaser, R. (2002). Depression and immune function: central pathways to morbidity and mortality. Journal of psychosomatic research, 53(4), 873-876. doi: 10.1016/S0022-3999(02)00309-4

Kiecolt-Glaser, J. K., McGuire, L., Robles, T. F., \& Glaser, R. (2002). Psychoneuroimmunology: psychological influences on immune function and health. Journal of consulting and clinical psychology, 70(3), 537.

Kubzansky, L. D., Kawachi, I., Weiss, S. T., \& Sparrow, D. (1998). Anxiety and coronary heart disease: a synthesis of epidemiological, psychological, and experimental evidence. Annals of Behavioral Medicine, 20(2), 4758. doi: $10.1007 / \mathrm{BF} 02884448$ 
Kuppens, P., Realo, A., \& Diener, E. (2008). The role of positive and negative emotions in life satisfaction judgment across nations. Journal of personality and social psychology, 95, 1, 66. doi: 10.1037/0022-3514.95.1.66

Lyubomirsky, S., King, L. \& Diener, E. (2005).The benefits of frequent positive Affect. Does happiness lead to success? Psychological Bulletin, 6, 803-855. doi: 10.1037/0033-2909.131.6.803

Pennebaker, J. W. (2000). Psychological factors influencing the reporting of physical symptoms. In A. A. Stone, J. S. Turkkan, C. A. Bachrach, J. B. Jobe, H. S. Kurtzman \& B. S. Cain (Eds.), The science of self-report: Implications for research and practice, (pp. 299-315). New Jersey: LEA.

Pressman, S. D. \& Cohen, S. (2005). Does Positive Affect Influence Health? Psychological Bulletin, 6, 925-971. doi: 10.1037/0033-2909.131.6.925

Ryff, C. D. (1989). Happiness is everything, or is it? Explorations on the meaning of psychological well-being. Journal of Personality and Social Psychology, 57, 1069-1081. doi: 10.1037/0022-3514.57.6.1069

Ryff, C. D. (2013). Eudaimonic well-being and health: Mapping consequences of self-realization. Waterman, A. S. (Ed). The best within us: Positive psychology perspectives on eudaimonia, (pp. 77-98). Washington, DC, US: American Psychological Association,

Ryff, C. D., Singer, B. H., \& Love, G. D. (2004). Positive health: Connecting well-being with biology. Philosophical Transactions-Royal Society of London Series B Biological Sciences, 1383-1394. doi: 10.1098/rstb.2004.1521

Sandín, B., Chorot, R, Lostao, L., Joiner, T.E., Santed, M.A., \& Valiente, R.M. (1999). Escalas PANAS de afecto positivo y negativo: Validación factorial y convergencia transcultural. Psicothema, II, 37-51.

Segerstrom, S. C., \& Sephton, S. E. (2010). Optimistic Expectancies and Cell-Mediated Immunity The Role of Positive Affect. Psychological science, 21, 3, 448-455. doi: 10.1177/0956797610362061
Setpoe, A. Dockray, S. \& Wardle, J. (2009). Positive Affect and Psychobiological Processes Relevant to Health. Journal of Personality, 6, 1747-1776.

Steiger, J. H. (1990). Structural model evaluation modification: An interval estimation approach. Multivariate Behavioral Research, 25, 173-180. doi: $10.1207 / \mathrm{s} 15327906 \mathrm{mbr} 2502 \_4$

Suh, E., Diener, E., Oishi, S., \& Triandis, H. C. (1998). The shifting basis of life satisfaction judgments across cultures: Emotions versus norms. Journal of personality and social psychology, 74, 2, 482. doi: 10.1037/0022-3514.74.2.482

Todaro, J. F., Shen, B. J., Niaura, R., Spiro, A., \& Ward, K. D. (2003). Effect of negative emotions on frequency of coronary heart disease (The Normative Aging Study). The American journal of cardiology, 92, 8, 901-906.

Watson, D., Clark, L. A., \& Tellegen, A. (1988). Development and validation of brief measures of Positive and Negative Affect: The PANAS Scales. Journal of Personality and Social Psychology, 54, 1063-1070. doi: 10.1037/0022-3514.54.6.1063

Watson, D. (1988). Intraindividual and interindividual analyses of positive and negative affect: their relation to health complaints, perceived stress, and daily activities. Journal of personality and social psychology, 54, 6, 1020. doi: 10.1037/0022-3514.54.6.1020

Yung, Y. F., Thissen, D., \& McLeod, L. (1999). On the relationship between the higher-order factormodel and the hierarchical factormodel. Psychometrika, 64, 113-128.

(Article received: 23-10-2015; revised: 23-03-2016; accepted: 23-05-2016) 